\title{
Yolk Sac Tumor of the Ovary in 18 Egyptian Cases: Does It Really Differ?
}

\author{
Ahmed Elsayed Fathalla1*, Hala Aziz Shokralla ${ }^{2}$ \\ ${ }^{1}$ Department of Surgical Oncology, National Cancer Institute, Cairo, Egypt \\ ${ }^{2}$ Department of Medical Oncology, National Cancer Institute, Cairo, Egypt \\ Email: *drasf1975@hotmail.com
}

Received 26 February 2016; accepted 4 April 2016; published 7 April 2016

Copyright (C) 2016 by authors and Scientific Research Publishing Inc.

This work is licensed under the Creative Commons Attribution International License (CC BY). http://creativecommons.org/licenses/by/4.0/

(c) (i) Open Access

\section{Abstract}

Background: Ovarian Yolk sac tumor (OYST) is a rare entity of malignant ovarian germ cell tumors (MOGCT). Abdominal pain, a rapidly growing distending mass or irregular vaginal bleeding is the main presentation. Serum AFP is elevated in nearly all cases. The standard management is fertility preserving surgery with adjuvant chemotherapy. Aim of Work: To report and analyze retrospectively recorded cases that were either treated at National Cancer Institute/Egypt or referred there for advice about therapy. Materials and Methods: This is a retrospective single-institutional analysis of 18 cases of OYST treated at National Cancer Institute-Cairo University from January 2011 till December 2015. The clinical and pathological characteristics, treatment, and outcomes of these patients were analyzed. Results: Data from eighteen patients were obtained. The median age was 18 years (range: 15 - 22). Abdominal pain was the most common presentation (89\%). The mean tumor size was $21 \mathrm{~cm}$ (range: $8-30 \mathrm{~cm}$ ). Eleven of our cases $(61 \%)$ were stage I, seven cases and $(39 \%)$ were stage IV at presentation. Fifteen cases $(83 \%)$ underwent fertility preserving procedure $\&$ the standard surgical staging. Panhysterectomy $\&$ formal staging procedure was done only in two cases $(11 \%)$. One case $(6 \%)$ underwent bilateral salpingo-oophorectomy. 2 cases $(11.1 \%)$ only underwent lymph node biopsy. 11 patient $(61.1 \%)$ showed pure type YST while mixed type was present in the remaining 7 cases (38.8\%): Dysgerminoma (one case, 5.6\%), Dysgerminoma + immature teratoma (one case, 5.6\%), Immature teratoma ( 2 cases, $11.1 \%$ ) and Teratoma ( 3 cases, $16.7 \%$ ). AFP was extremely elevated in all cases at presentation (median $4191 \mathrm{ng} / \mathrm{mL}$; ranging: $725 \mathrm{ng} / \mathrm{mL}-402,908 \mathrm{ng} / \mathrm{mL}$ ). It showed decreased level after surgery (median $145 \mathrm{ng} / \mathrm{mL}$; ranging: $2 \mathrm{ng} / \mathrm{mL}-\mathbf{3 8 , 0 0 0} \mathrm{ng} / \mathrm{mL}$ ) \& normalized after chemotherapy except for progressive disease. All cases started BEP regimen after surgery with complete remission in twelve cases. In follow up period (median 17 months; ranging: $\mathbf{2}$ - 48 months) two patients relapsed; the mean overall survival time was 34.2 and progression free survival was 33.84 months respectively. Conclusion: Ovarian yolk sac tumors are rare neoplasms. Surgery with adjuvant chemotherapy is the standard management. AFP is important for diagnosis, monitoring response to treatment and predicting re-

"Corresponding author. 
lapse.

Keywords

Yolk Sac Tumor, Ovary, Outcomes

\section{Introduction}

Ovarian yolk sac tumor (OYST), also known as endodermal sinus tumor is a rare tumor comprising 1\% of all ovarian malignancies. It was first proposed in 1939 by Schiller, who discovered an ovarian tumor with a mesonephroid origin. 20 years later, Teilum classified this embryological origin and named them endodermal sinus tumors [1] [2].

It accounts for $20 \%$ of all malignant ovarian germ-cell tumors (MOGCTs) being the second most frequent histological subtype, after ovarian dysgerminoma. They were called OYSTs because of the similarity of this tumor with the extraembryonal yolk sac and vitelline structures [3].

It usually occurs at younger age groups (children and adolescents) with abdominal pain associated with a rapidly growing mass. It may also present with per vaginal bleeding [3] [4].

The primary evaluation should include CA125 as well as germ-cell tumor markers [AFP, b-HCG and LDH]. This will help to distinguish between epithelial and non-epithelial ovarian tumors before surgery which should be optimized accordingly. These tumors are frequently associated with elevated level of Serum alpha-fetoprotein (AFP) which is used as a useful marker for its diagnosis and management [5].

We are aiming to report retrospectively recorded cases that are either treated at National Cancer Institute/ Egypt or referred there for advice about therapy. Data on patient characteristics, management and survival were collected and analyzed.

\section{Materials and Methods}

All patients treated for ovarian OYST during the period from January 2011 to December 2015 at the National Cancer Institute, Cairo University, Egypt were investigated retrospectively. Data for age, clinical manifestations, serum tumor markers, staging, diagnostic procedures and treatment protocols were reviewed and analyzed. Ethical clearance for the conduction of this study was obtained from our institute ethical committee.

\section{Results}

\subsection{Clinical Features}

Eighteen cases of OYST were included in this study. The patients ranged in age from 15 to 22 years (median 18 years). The commonest presentation was abdominal pain (16 cases, 89\%) followed by abdominal distension (12 cases, 67\%), vaginal bleeding unrelated to menses (4 cases, 22\%). Seventeen patients (94\%) presented with unilateral disease and only a single case showed bilateral ovarian masses. Neoplasms were grossly identified and ranged in size from 8 to $30 \mathrm{~cm}$ (median: $21 \mathrm{~cm}$ ). AFP was elevated in all our cases at presentation (mean 33,815 $\mathrm{ng} / \mathrm{mL}$ ), while CA125, LDH and b-HCG were of normal values throughout all our cases.

\subsection{Staging}

Tumors were staged according to FIGO staging system; at presentation we have 11 cases (61\%) were stage I and only seven cases (39\%) were stage IV.

A summary of our patients' characteristics at presentation are presented in Table 1.

\subsection{Treatment}

Surgery was performed for all cases aiming for removing the primary tumor, obtaining an accurate histological diagnosis and to assess the disease extent. In young women, fertility-sparing surgery should be performed, in order to preserve the possibility of pregnancy later on. 
Table 1. Summary of patients’ characteristics at presentation.

\begin{tabular}{|c|c|}
\hline Patient characteristic in our study & No. $(\%)$ \\
\hline $\begin{array}{l}\text { Age at presentation (years) } \\
<18 \text { year } \\
\geq 18 \text { year }\end{array}$ & $\begin{array}{c}6(33 \%) \\
12(67 \%)\end{array}$ \\
\hline $\begin{array}{l}\text { Stage } \\
\text { - I } \\
\text { - } \quad \text { IV }\end{array}$ & $\begin{array}{c}11(61 \%) \\
7(39 \%)\end{array}$ \\
\hline $\begin{array}{l}\text { Tumor bilaterality } \\
\text { - Unilateral } \\
\text { - } \quad \text { Bilateral }\end{array}$ & $\begin{array}{c}17(94 \%) \\
1(6 \%)\end{array}$ \\
\hline Tumor size & $21 \mathrm{~cm}(8-30 \mathrm{~cm})$ \\
\hline $\begin{array}{l}\text { Histology } \\
\text { Pure } \\
\text { Mixed } \\
\text { - Dysgerminoma } \\
\text { - Dysgerminoma + immature teratoma } \\
\text { - Immature teratoma } \\
\text { - } \quad \text { Teratoma }\end{array}$ & $\begin{array}{c}11(61.1 \%) \\
7(38.8 \%) \\
1(5.6 \%) \\
1(5.6 \%) \\
2(11.1 \%) \\
3(16.6 \%)\end{array}$ \\
\hline Pleural effusion & $3(17 \%)$ \\
\hline Ascites (intraoperative) & $5(28 \%)$ \\
\hline $\begin{array}{l}\text { Symptoms } \\
\text { Pain } \\
\text { Distension } \\
\text { Vaginal bleeding }\end{array}$ & $\begin{array}{c}16(89 \%) \\
12(67 \%) \\
4(22 \%)\end{array}$ \\
\hline
\end{tabular}

Fifteen cases (83\%) underwent fertility preserving procedure (unilateral salpingo-oophorectomy \& standard surgical staging). Panhysterectomy was done in only two cases (11\%); (total abdominal hysterectomy and bilateral salpingo-oophorectomy with the standard surgical staging procedure). The standard surgical staging consists of peritoneal washing, peritoneal biopsies, infracolic omentectomy, and any suspicious lesion biopsy. One case underwent bilateral salpingo-oophorectomy as there was obvious complete destruction of both ovaries by the tumor intraoperatively with no apparent ovarian tissue left. This patient was not consented to complete the procedure with total abdominal hysterectomy. Appendicectomy and ileal segment resection anastomosis was performed in 4 separate cases (22.2\%) as a part of the surgical procedure needed. Only 2 cases $(11.1 \%)$ underwent nodal assessment in the form of lymph node biopsy (one from pelvic lymph nodes and the other from paraaortic group of lymph nodes). The pathological subtype revealed pure YST in 11 patient (61.1\%) and mixed YST in the remaining 7 cases (38.8\%) as follows: Dysgerminoma (one case, 5.6\%), Dysgerminoma + immature teratoma (one case, 5.6\%), Immature teratoma (2 cases, 11.1\%) and Teratoma (3 cases, 16.7\%).

All cases received post-operative chemotherapy, starting from stage I disease in the form of 4 to 6 courses of the BEP (Bleomycin-Etoposide-Platinol) regimen. Only two cases that did not complete their adjuvant chemotherapy and lost follow up shortly after starting. Details of treatment given to our patients are presented in Table 2.

After treatment; all cases were in complete remission apart of two only who progressed after. Progression was in form of increasing size of pelvic or abdominal nodes with biological rise of AFP level.

\subsection{Survival}

During the period of follow-up (mean 28.8 months, ranging from 2 - 48 months), two cases relapsed as pulmonary, hepatic and omental deposits. Relapse was suspected with patients complain and AFP rising levels. Both 
Table 2. Details of treatment received in our cases.

\begin{tabular}{lc}
\hline \multicolumn{1}{c}{ Details of treatment received in our cases } & No. (\%) \\
\hline Surgery & \\
- Fertility preserving & $\mathbf{1 5}(\mathbf{8 3 \% )}$ \\
- Panhysterectomy & $\mathbf{2 ( 1 1 \% )}$ \\
- Omentectomy & $\mathbf{1 1}(\mathbf{6 1 \% )}$ \\
- Appendectomy & $\mathbf{2 ( 1 1 \% )}$ \\
- Ileal segment resection & $\mathbf{2 ( 1 1 \% )}$ \\
- Pelvic LN biopsy & $\mathbf{1 ( 6 \% )}$ \\
- Paraaortic LN biopsy & $\mathbf{1 ( 6 \% )}$ \\
& \\
Residual disease & \\
- No gross residual & $\mathbf{1 2 ( 6 7 \% )}$ \\
- $>1$ cm & $\mathbf{1 ( 6 \% )}$ \\
Adjuvant BEP regimen (No. of cycles) & $\mathbf{5 ( 2 7 \% )}$ \\
$4-6$ & \\
1 - 2 & $\mathbf{1 6 ( 8 9 \% )}$ \\
\hline
\end{tabular}

patients died of the disease during or shortly after salvage chemotherapy.

The mean overall 5 years survival for all cases was 34.2 months (95\% Confidence Interval: 25.1 - 43.3 months). Standard error of the mean (SE) was 4.6 (Figure 1).

At end of our study patients, twelve cases (67\%) were still alive free of the disease. The mean overall disease free survival was 33.84 months (95\% Confidence Interval: 24.5 - 43.2 months). Standard error of the mean (SE) was 4.7 (Figures 2-5).

\section{Discussion}

OYST are classified as GCT, and their occurrence is rare, representing approximately $1 \%$ of all ovarian malignancies and 20\% of MOGCT. They are commonly seen in children and young adolescent [6]. In our cohort the median age was 18 years.

OYSTs usually present as a unilateral mass, with both cystic and solid components that ranged in size in most studies from $(5-30 \mathrm{~cm})$ with a mean diameter of $13 \mathrm{~cm}$. these results were matching to our work; our median size was $21 \mathrm{~cm}$ (ranging; $8-30 \mathrm{~cm}$ ) and 94\% of our cases were unilateral [6] [7].

Patients may present with abdominal pain, abdominal distension related to mass effects, ascites, menstrual irregularities or intermenstural bleeding. In our report we have 16 cases presented with pain, 12 cases with distension and 4 cases with bleeding [3] [8].

Serum CA-125 is not correlated to this tumor as in epithelial types; instead serum AFP is usually pathognomonic and shows high sensitivity and specificity for its diagnosis. AFP serum marker is important for diagnosis, recurrence and detection of disease progression. All our cases (100\%) showed elevated serum AFP at diagnosis (median: $4191 \mathrm{ng} / \mathrm{ml}$ ) [9].

Multi factors are determining the prognosis of this tumor. The most important are stage, age, tumor size, type of surgery done \& tumor rupture during surgery. In this cohort we were not able to report any of them due small numbers of cases to be evaluated statistically [10].

In most of publications, patients usually present at early stage i.e. stage I disease (70\% - 90\%), thus having a very favorable prognosis and better outcome. In this cohort $61 \%$ of our patients were stage I disease [11].

Complete tumor resection is the mainstay of treatment with fertility preserving procedure for early disease and tumor debulking for advanced disease together associated with formal surgical staging. Adjuvant treatment for OYSTs in now standardized and is usually recommended for all stages of the disease. Chemotherapy typically includes a combination of platinum based chemotherapy, the most common of which is BEP regimen. In the current study all cases were given BEP (bleomycin $30 \mathrm{U}$ on days 2 , 9, and 16, etoposide $100 \mathrm{mg} / \mathrm{m}^{2} /$ day on days 1 - 5, and cisplatin $20 \mathrm{mg} / \mathrm{m}^{2} /$ day on days 1 - 5) administered every 3 weeks for 4 - 6 courses according to tumor response [11]-[13].

Complete cure with a long disease free interval is more readily obtained by surgery with adjuvant BEP regimen 


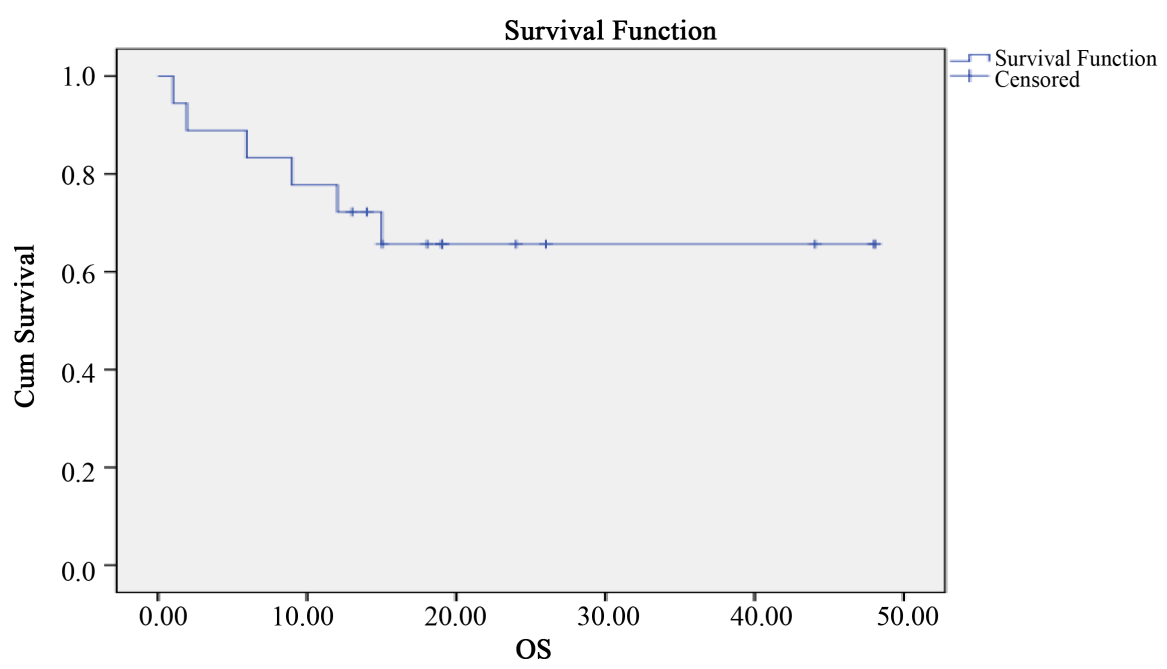

Figure 1. Overall survival of all cases.

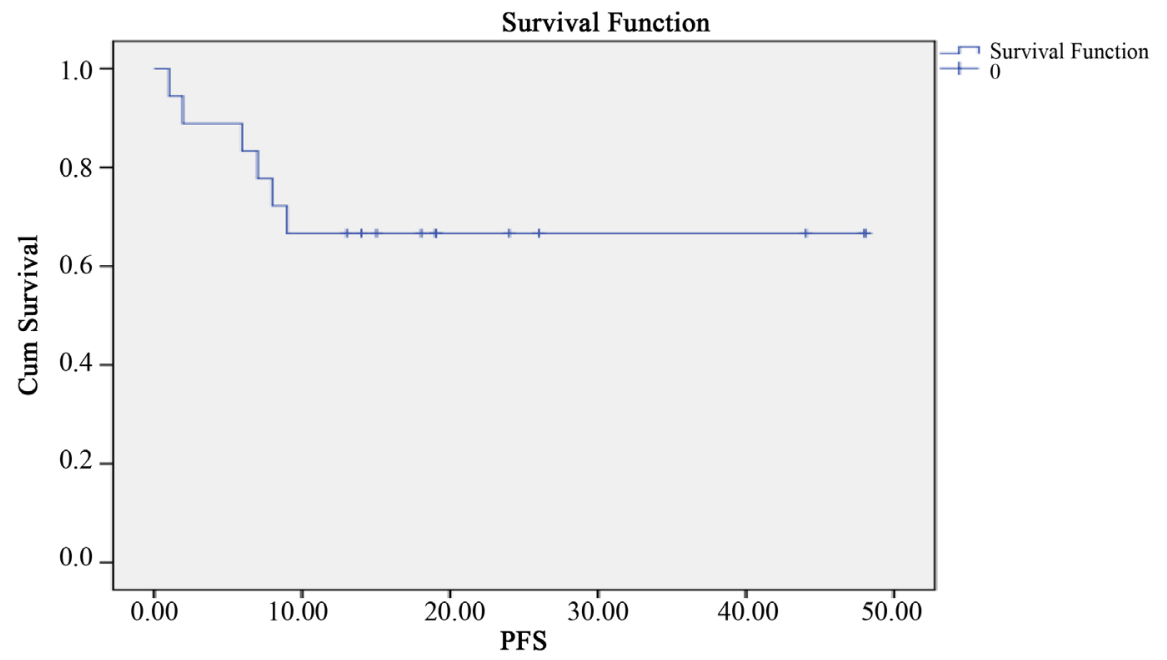

Figure 2. Progression free survival of our cases.
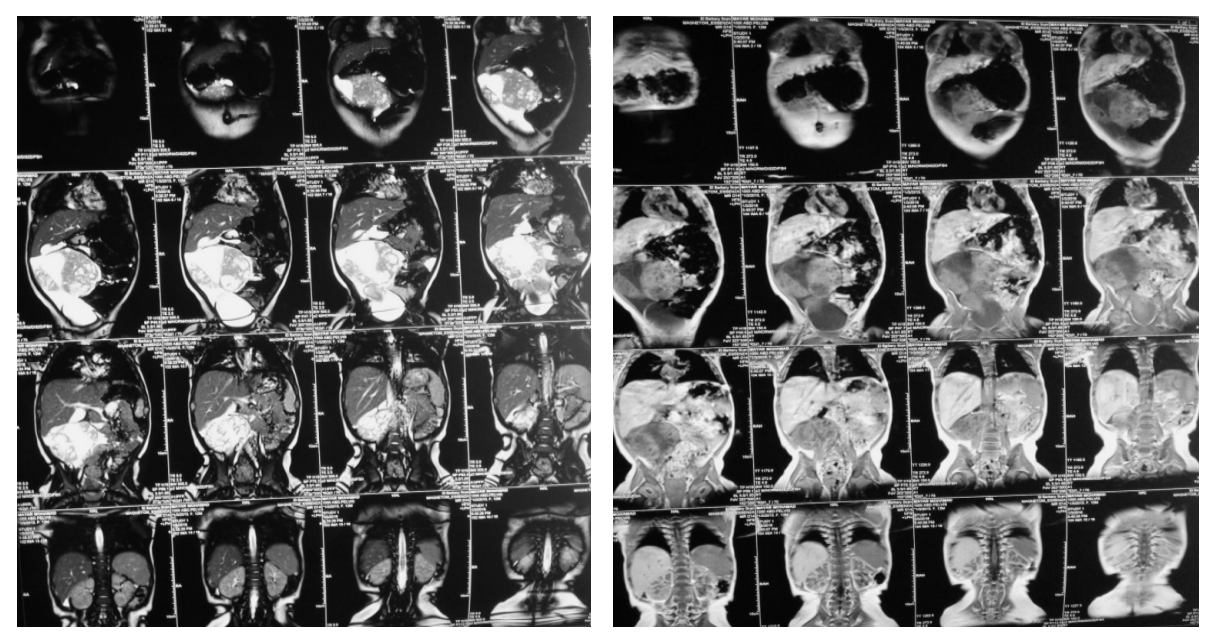

Figure 3. MRI (T1 \& T2 weighted images), coronal views showing a large right adnexal cyst of one of our ovarian YSTs cases. 

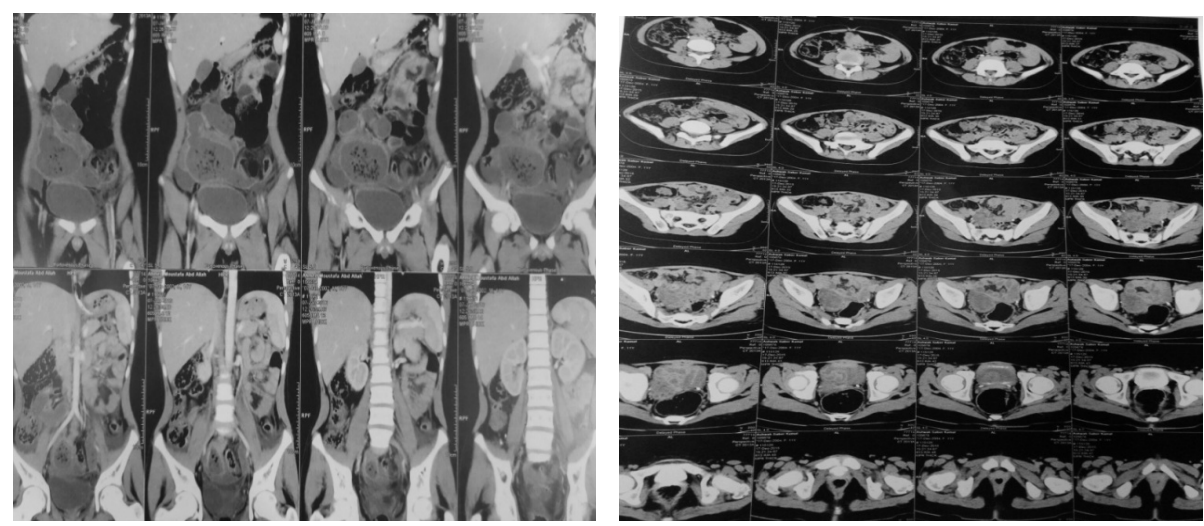

Figure 4. CT scan of 2 patients with YSTs (coronal \& axial views) showing the fat content of the right ovarian mass.
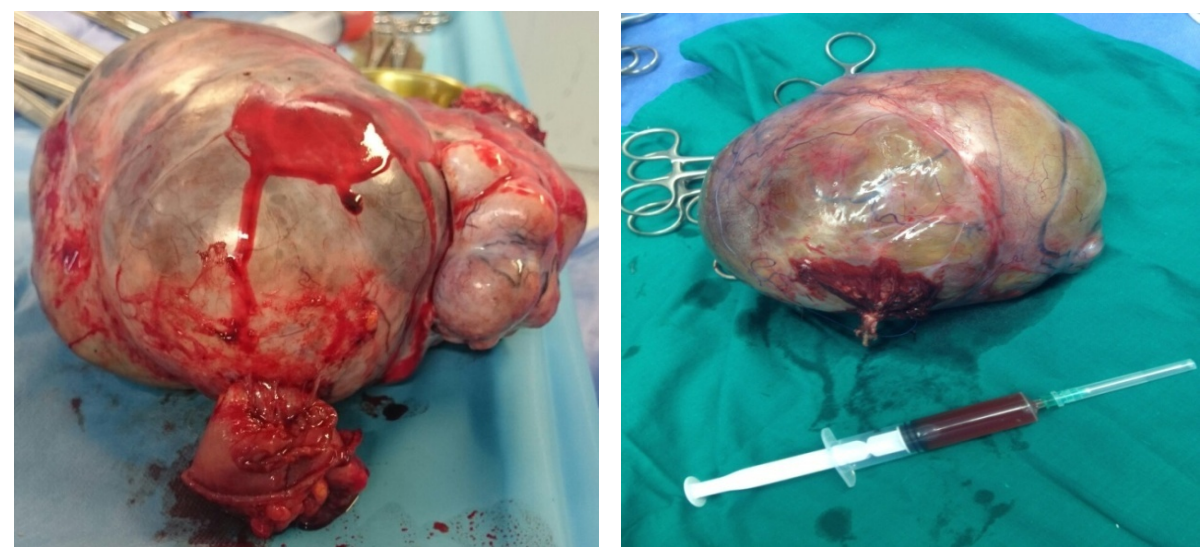

Figure 5. Postoperative specimen of 2 of our patients with right adenexal masses after a fertility preserving procedure.

chemotherapy. In our study all cases, all cases respond to treatment and stay disease free apart of 2 cases that progressed after chemotherapy [14].

The mean follow up period was 28.8 months; two patients suffered disease relapse in form of biological relapse (rising of AFP) and radiological relapse (pulmonary, hepatic and omental metastasis)

A controversy still exists regarding how to treat a relapsed disease. Distant organ failure may still need a second line therapy which is usually single agent chemotherapy [15] [16].

\section{Conclusion}

Ovarian YSTs are rare neoplasms. As a result of the rarity of this tumor, specific survival and outcome after such treatment are not well known. Several publications are still needed to establish a consensus for optimum prognostic factors and survival rates.

\section{References}

[1] Teilum, G. (1959) Endodermal Sinus Tumors of the Ovary and Testis. Comparative Morphogenesis of the So-Called Mesoephroma Ovarii (Schiller) and Extraembryonic (Yolk Sac-Allantoic) Structures of the Rat's Placenta. Cancer, 12, 1092-1105. http://dx.doi.org/10.1002/1097-0142(195911/12)12:6<1092::AID-CNCR2820120606>3.0.CO;2-V

[2] Yao, X.D., Hong, Y.P., Ye, D.W. and Wang, C.F. (2012) Primary Yolk Sac Tumor of Seminal Vesicle: A Case Report and Literature Review. World Journal of Surgical Oncology, 10, 189. http://dx.doi.org/10.1186/1477-7819-10-189

[3] Smith, H.O., Berwick, M., Verschraegen, C.F., Wiggins, C., Lansing, L., Muller, C.Y., et al. (2006) Incidence and Survival Rates for Female Malignant Germ Cell Tumors. Obstetrics \& Gynecology, 107, 1075-1085.

http://dx.doi.org/10.1097/01.AOG.0000216004.22588.ce 
[4] Van Thielen, T., Degryse, H. and Coeman, D. (2013) Yolk Sac Tumor of the Ovary. JBR BTR, 96, 256-257. http://dx.doi.org/10.5334/jbr-btr.313

[5] Dallenbach, P., Bonnefoi, H. and Pelte, M.F. (2006) Yolk Sac Tumors of the Ovary: An Update. EJSO, 32, $1063-1075$. http://dx.doi.org/10.1016/j.ejso.2006.07.010

[6] Schneider, D.T., Calaminus, G., Koch, S., Teske, C., Schmidt, P., Haas, R.J., et al. (2004) Epidemiologic Analysis of 1442 Children and Adolescents Registered in the German Germ Cell Tumor Protocols. Pediatric Blood \& Cancer, 42, 169-175. http://dx.doi.org/10.1002/pbc.10321

[7] Nawa, A., Obata, N., Kikkawa, F., Kawai, M., Nagasaka, T., Goto, S., et al. (2001) Prognostic Factors of Patients with Yolk Sac Tumors of the Ovary. American Journal of Obstetrics \& Gynecology, 184, 1182-1188. http://dx.doi.org/10.1067/mob.2001.113323

[8] Dallenbach, P., Bonnefoi, H., Pelte, M.F. and Vlastos, G. (2006) Yolk Sac Tumours of the Ovary: An Update. European Journal of Surgical Oncology, 32, 1063-1075. http://dx.doi.org/10.1016/j.ejso.2006.07.010

[9] Nogales, F.F., Dulcey, I. and Preda, O. (2014) Germ Cell Tumors of the Ovary: An Update. Archives of Pathology \& Laboratory Medicine, 138, 351-362. http://dx.doi.org/10.1016/j.ejso.2006.07.010

[10] Goyal, L.D., Kaur, S. and Kawatra, K. (2014) Malignant Mixed Germ Cell Tumour of Ovary—An Unusual Combination and Review of Literature. Journal of Ovarian Research, 7, 91. http://dx.doi.org/10.1186/s13048-014-0091-5

[11] Kojimahara, T., Nakahara, K., Takano, T., Yaegashi, N., Nishiyama, H., et al. (2013) Yolk Sac Tumor of the Ovary: A Retrospective Multicenter Study of 33 Japanese Women by Tohoku Gynecologic Cancer Unit (TGCU). The Tohoku Journal of Experimental Medicine, 230, 211-217. http://dx.doi.org/10.1620/tjem.230.211

[12] Tangir, J., Zelterman, D., Ma, W. and Schwartz, P.E. (2003) Reproductive Function after Conservative Surgery and Chemotherapy for Malignant Germ Cell Tumors of the Ovary. Obstetrics \& Gynecology, 101, 251-257. http://dx.doi.org/10.1097/00006250-200302000-00010

[13] Gershenson, D.M., Miller, A.M., Champion, V.L., Monahan, P.O., Zhao, Q., Cella, D., et al. (2007) Reproductive and Sexual Function after Platinum-Based Chemotherapy in Long-Term Ovarian Germ Cell Tumor Survivors: A Gynecologic Oncology Group Study. Journal of Clinical Oncology, 25, 2792-2797. http://dx.doi.org/10.1200/JCO.2006.08.4590

[14] Schmoll, H.J., Souchon, R., Krege, S., Albers, P., Beyer, J., Kollmannsberger, C., et al. (2004) European Consensus on Diagnosis and Treatment of Germ Cell Cancer: A Report of the European Germ Cell Cancer Consensus Group (EGCCCG). Annals of Oncology, 15, 1377-1399. http://dx.doi.org/10.1093/annonc/mdh301

[15] Brewer, M., Gershenson, D.M., Herzog, C.E., Mitchell, M.F., Silva, E.G. and Wharton, J.T. (1999) Outcome and Reproductive Function after Chemotherapy for Ovarian Dysgerminoma. Journal of Clinical Oncology, 17, 2670-2675.

[16] Hazarika, P. (2015) Endometrioid Like Yolk Sac Tumor of the Testis with Small Teratomatous Foci: A Case Report and Review of the Literature. Indian Journal of Pathology and Microbiology, 58, 557-559. 